\title{
On the Breeding Habits of Echinus miliaris, with a Note on the Feeding Habits of Patella vulgata.
}

\author{
By \\ J. H. Orton, B.Sc,, A.R.C.Sc. \\ With One Figure in the Text.
}

WHILE on shore-collecting expeditions in this district it was frequently observed that Echinus miliaris has the habit of associating together in pairs, and sometimes in groups of more than two.* The association of these pairs and groups is sometimes so intimate that it is not possible to interpose even the blade of a penknife between the interlocking spines of the urchins. In all cases observed except one, such pairs were placed side by side, but in one particular case the apical region of one individual was almost certainly placed adjacent to the apical portion of the other. In all the collecting expeditions $\uparrow$-made at various times of the year between April and August-on which groups were collected, the total number of urchins of all sizes obtained amounts to about 710 . Among this number were obtained 84 groups, which amount in all to 189 specimens. In the earlier part of the investigation a group was taken as such if the members were merely fairly close together, but afterwards only those specimens were recorded which were actually touching one another in the manner described above. Out of the total of 84 groups only 27 were actually recorded definitely as touching one another, although some of the other groups may have been touching. Of these 27 closely associated forms all the individuals were ripe except 3 small specimens belonging to two pairs which were recorded as having an immature gonad. The remainder consisted of 19 pairs $\hat{\delta}+, 2$ pairs

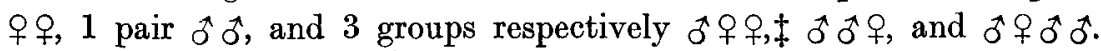
These facts in themselves point to the conclusion that in $E$. miliaris

\footnotetext{
* In a few cases as many as from 13 to 21 individuals have been found close together under one stone.

† In the search for groups of these urchins I am much indebted to the laboratory fisherman, William Searle, for the zeal and care with which he helped in the collecting.

$¥$ In this group the $q$ associated with the male was almost certainly spent, although it was difficult to make certain whether on the other hand it might be immature. Hence it is not grouped with the definite pairs of male and female.
} 
there is a distinct instinct for association of individuals at the time of sexual maturity, and that the association frequently, but not always, results in pairing of the sexes. In this respect the position in which two of the above pairs of male and female were taken is specially interesting. Both pairs were situated under a large stone whose lower surface was somewhat rectangular, and would measure rather more than two feet on the longer axis. The pairs were on the opposite ends of the lower surface near the edge of the stone on the long axis, and each member of a pair was closely opposed to the other. It would thus appear that these four urchins had definitely mated in pairs.

Of the 57 remaining groups taken, 41 contained all ripe individuals, and combining these 41 groups with those given above, it was found that out of the total of 66 associations of ripe specimens, 41 were 0 \% 9 of various sexes, 8 우, 6 of and 2 우아. Thus in all the groups of ripe forms there were 40 pairs of opposite sexes and $8+6+2=16$ groups exclusively of one sex or the other. Therefore, leaving out the 9 groups containing various sexes, it is seen that the number of pairs, namely 41 , is greater than twice the number of the groups which contain one sex or the other. Consequently it is highly probable that the statement that the sexes of $E$. miliaris associate definitely for the purpose of breeding is significant.

In the whole of the groups collected, regardless of ripeness of the gonad in all the members of the group, there were 47 pairs of $\delta$ and $q$, 15 pairs $q+q, 6$ of 8 groups of more than two containing both sexes, 2 groups $q+\varphi+, 1$ $1 \widehat{\delta} \delta$, and 5 containing one or more immature forms. In the groups recorded as not all ripe there were some specimens quite ripe. Many of the other urchins in these groups, however, would probably have yielded some embryos if their sex cells had been mixed with those from similar forms of the opposite sex, but an attempt based on experience was made to name those forms ripe which would probably have yielded a good proportion of segmenting eggs as a result of fertilization. In this branch of the investigation I am indebted to Mr. H. M. Fuchs for some help in determining the state of the gonad.

A more significant result could doubtless be obtained by an examination of a larger number of pairs of $E$. miliaris obtained about the same time and during the breeding season, but the opportunities for such an investigation are not very common. $E$. miliaris can often be taken in numbers by dredging, and then I have frequently observed that many individuals are taken matted together, and in such a way as to suggest they were actually in that condition before being captured by the dredge. 
In the same way large hauls of E. esculentus and E. acutus and relatively* large hauls of Echinocardium cordatum can frequently be made on certain grounds in hauls of not more than 10 to 15 minutes, but it is equally uncertain here, as in the case of the dredged $E$. miliaris, that there is any association in pairs; nevertheless it is not improbable that the

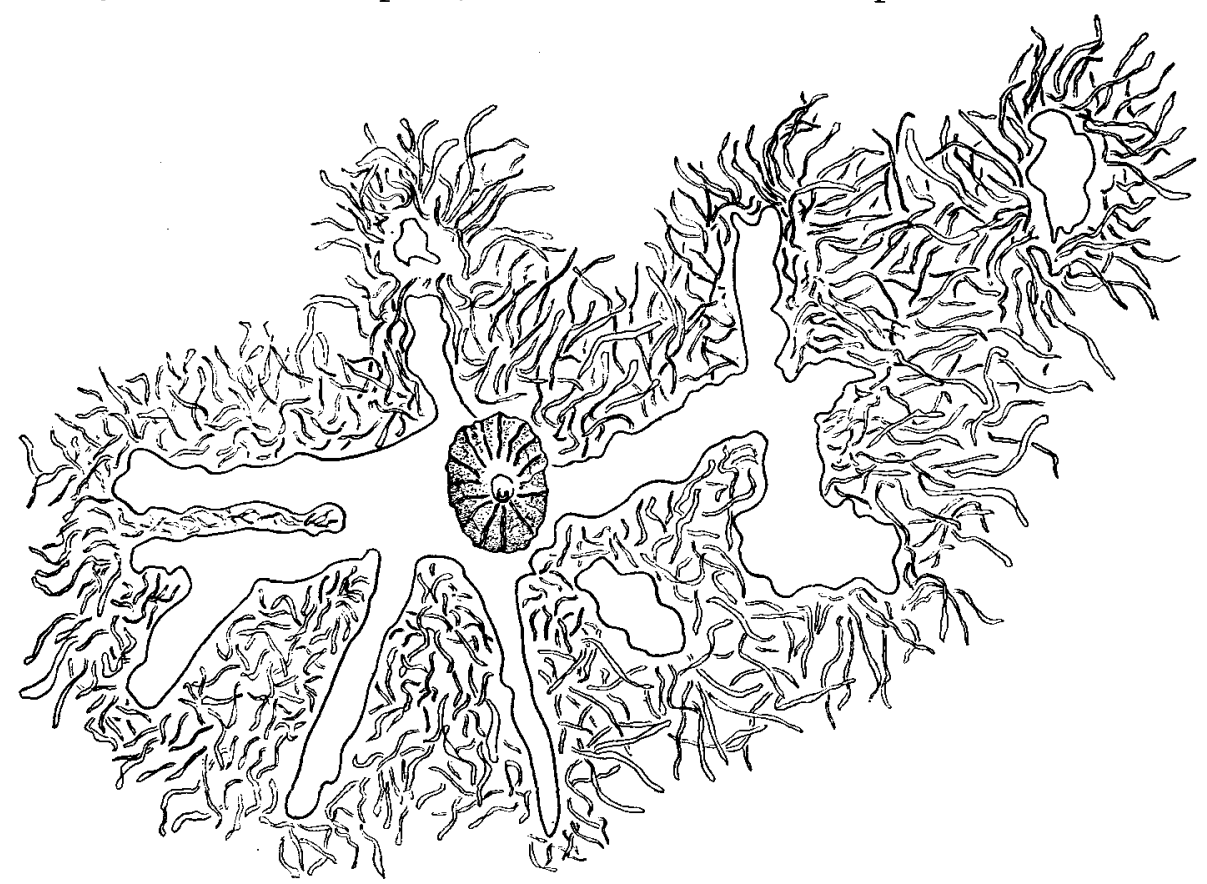

Fig. 1. $†-A$ view of Patella showing the food-paths it has eaten in a growth of green alge, chiefly young Enteromorpha ( $\frac{2}{3}$ natural size).

The limpet is shown on its "home," from which it has made excursions in various directions and to which it has afterwards returned.

aggregation of such large numbers of individuals might be in part for the purpose of spawning, since such hauls may be taken when all these species are ripe.

Tennent has observed $\ddagger$ in Toxopneustes that "when these animals are

* Echinocardium cordatum when living in deep water inhabits fine sand, from which it can only be captured by means of a dredge, and in a 3-foot dredge a short haul may sometinles yield as many as 15 individuals. This species occurs in great numbers in the Salcombe estuary within a very small area, but this aggregation is probably due more to the presence of only a small area of suitable ground than to a desire of the individuals to associate. Nevertheless in this locality these heart-urchins associate closely in groups of twos, threes, and sometimes in larger numbers. The sexes of the members of such groups have not, however, been observed.

† I am indebted to Mrs. Orton for the drawing for this figure, which has been copied from a sketch made in my collecting book.

+ D. H. Tennent, Journ. Exp. Zool., Vol. IX, No. 4, p. 659, 1910. 
ready to spawn they gather more or less closely together," and Hertwig* mentions that "egg-deposition may provide sexual stimulation to the males, since when a large number of urchins are placed together in seawater as soon as the females begin to discharge eggs the males spawn." It is not improbable, therefore, that association of the sexes for the purpose of spawning may be common throughout the Echinoids.

\section{Note on the Feeding Habits of Patella.}

It is well known that Patella obtains its food by browsing on both the smaller and larger forms of algæ. $\dagger$ Striking evidence of this fact has, however, been obtained and is worth noting. In observing specimens of Patella situated on cement piles above low-water mark, it was noticed that the animals had in many cases eaten away paths in the green algæ, chiefly young Enteromorpha, by which they were surrounded. The paths radiate from the "scar" of the animal, and are marked with fine lines made by the teeth on the radula. These paths are shown in Fig. 1. In several cases the animal had travelled beyond the end of the path formerly eaten before beginning to browse again, and afterwards returned home to its scar. (See Fig. 1.) Such configurations as that shown in the figure are by no means uncommon on the pier walls in this district in situations favourable for the growth of algæ. As the alga grows the food-paths of the limpet may become more marked, and in some cases the spatting of Balanus balanoides along the paths makes them so evident that they are easily seen from some distance away.

* O. Hertwig, Zeit. für Wiss. Zool. Jen., Vol. XXIV, p. 282, 1890.

$\dagger$ J. R. Ainsworth Davis and H. J. Fleure, Patella L.M.B.C. Memoir, Vol. X, London, 1903. 